\title{
Living Tensions of Co-Creating a Wellness Program and Narrative Inquiry Alongside Urban Aboriginal Youth
}

\author{
Lee Schaefer, Sean Lessard, and Brian Lewis
}

\begin{abstract}
This paper is based on a three-year study that has a dual purpose: firstly, to create a program to attend to the health and wellness of Aboriginal children and youth, and secondly, to narratively inquire into the experiences of the children and youth who participate in the wellness program. In an attempt to disrupt intervention type models that position Aboriginal youth as at-risk, or in-deficit, we pose questions around how wellness programming and research begin in different commitments when we see Aboriginal youth as knowledge holders.

\section{Living Tensions of Co-Creating a Wellness Program and Narrative Inquiry Alongside Urban Aboriginal Youth}

This paper is based on a study that has a dual purpose: firstly, to create a program to attend to the health and wellness of Aboriginal children and youth, and secondly, to narratively inquire into the experiences of the children and youth who participate in the wellness program. One purpose of this paper is to explore how research paradigms played a role in both our wellness program decisions and research design; it is within these pragmatic experiences that we are looking to contribute to the literature around community-based Aboriginal youth and wellness research. The second purpose of this paper is to attend to the tensions and bumping places that arose as we attempted to co-create, and maintain, a narrative inquiry alongside urban Aboriginal youth, their families, and their communities at the same time as we lived out a program funded to provide health and wellness opportunities for children and youth. In an attempt to disrupt intervention type models that position Aboriginal youth as at-risk, or in-deficit, we pose questions around how wellness programming and research begin in different commitments when we see Aboriginal youth as knowledge holders.
\end{abstract}

\section{From the Midst}

The bell rings to signal the end of the school day in this prairie city neighbourhood. The end of the school day also marks the beginning of Growing Young Movers, the physical movement and wellness program for youth that we are a part of. We always gather in a circle at the beginning of the program. Jade, a grade 4 student, and Tanya, who is in high school, pass around homemade muffins Jade's Grandma made for us. We begin simply, with a wonder about what is new in their busy lives. We are not surprised as Colt shares his excitement of getting a puppy compounded by his struggles of finding time to walk her before he catches his morning school bus. Brandon talks about his weekend at his Dad's place; Kerri shows the group her artwork from her school art class; Eric shares how delicious the muffin is. Each time we sit in a circle, we learn 
more about each other and we learn more about how we want to relate to one another within this physical place. Our sharing circle ends with laughter as we outline the plans for the rest of our time together which always includes physical movement activities, games and play. (Field Text, November 12, 2014)

We begin with this field text that gives a sense of our narrative inquiry alongside Aboriginal children and youth in an ongoing after school program (Growing Young Movers) that is positioned in a funded health and wellness research project. The opening fragment of our field text offers a glimpse, a snapshot of a moment within the gymnasium each week where we have learned the importance of opening up an intentional space to learn, to listen carefully, and honour the stories of experiences of Aboriginal children and youth. This might appear to some readers as attending to unnecessary details of Aboriginal kids telling stories that are not explicitly linked to wellness. Sitting in a circle in a wellness and physical activity research study may also be seen as detrimental to increasing moderate to vigorous physical activity (MVPA), which is the focus of many after school physical activity programs. However, we see these small intentional moments in other ways, as part of a larger ontological commitment to Aboriginal children and youth's experiences within community. We move this way in relationship with both intention and purpose.

The overall study has a dual purpose: firstly, to create a program to attend to the health and wellness of Aboriginal children and youth, and secondly, to narratively inquire into the experiences of the children and youth who participate in the wellness program. We come to this research with specific backgrounds and a desire to engage in community-based research alongside Aboriginal youth and families. Sean, one of the researchers, is Woodland Cree from the Montreal Lake Cree Nation in Northern Saskatchewan Treaty 6 territory. Sean participated in an earlier narrative inquiry alongside Aboriginal children and youth in an after-school art club in a junior high school (Lessard, 2015; Chung, 2016). The earlier study, designed to explore the experiences of Aboriginal youth both in and out of schools, established an art club where researchers and youth could come to know each other and where relationships could be nurtured that allowed researchers to move to outside of school places. In the design of the Growing Young Movers program, we drew on a similar design, albeit aware that the larger social, institutional, and funding narratives in our project were centrally designed with a program focus. It was in living out the dual purposes that we became attentive to the paradigms at work that created tensions and occasionally bumping places as we worked to offer a wellness program and engage in a narrative inquiry into children's and youth's experiences (Connelly \& Clandinin, 1999).

One purpose of this paper is to explore how research paradigms played a role in both our wellness program decisions and research design; it is within these pragmatic experiences that we are looking to contribute to the literature around community-based Aboriginal youth and wellness research. The children and youth know that they are participating in both a program and a narrative inquiry. As we live alongside children and youth in this after-school time period, in a school gymnasium place, we are attentive to the kind of space being co-composed between each of us that allows us to understand more about each other's lives and, in turn, each other's ideas of wellness. Attention to research spaces and paradigms matter. 
They matter because they tell us something important about the researcher's standpoint. They tell us something about the proposed relationship to Other(s)...They tell us how the researcher intends to take account of multiple conflicting and contradictory values she will encounter. (Lincoln, Lynham, \& Guba 2011, p. 7)

We have found that they also matter because when attended to carefully, the experienced tensions can teach us about bumping between paradigms, and possibly provide ways forward to think and respond attentively as community members and researchers.

The second purpose of this paper is to attend to the tensions and bumping places that arose as we attempted to co-create, and maintain, a narrative inquiry alongside urban Aboriginal youth, their families, and their communities at the same time as we lived out a program funded to provide health and wellness opportunities for children and youth. While universities and granting agencies strive to diversify knowledge translation, and to connect with communities, the grand narratives (Clandinin \& Connelly, 2000, Clandinin, 2007) surrounding research may not be coherent with the inclusion of communities outside of universities as knowledge holders. In this particular case, the need to research efficiently and garner generalizable results to meet funding deliverables clashed with what we have come to understand as narrative inquirers engaged in research with Aboriginal children, youth, and families that call us to move slowly in relationship to more fully understand, and take care of, the shared experiences. The Indigenous writer Cajete (1994) reminds us that, "community is the place where the forming of the heart and the face of the individual as one of the people is the most fully expressed" (p. 164). From our experiences in the Centre for Research for Teacher Education at the University of Alberta, from past narrative inquiries, and from working in Indigenous and non-Indigenous communities, we see participants, families, and communities, as rich with experiences and knowledge that help inform both practice and research. As we engaged alongside the children and youth, and lived out methodological commitments grounded in narrative inquiry as both research methodology and phenomenon under study (Clandinin \& Connelly, 2000), we identified bumping places that became apparent as we lived in the field and inquired into our field texts. We illustrate these bumping places in this paper. The opening field text reminds us that we are trying to hold open a space that allows us to stay awake to what matters in relation, to how we want to live alongside youth as narrative inquirers within a co-composed wellness research space at the same time as we lived out the plans for the health and wellness program.

\section{Narrative Inquiry}

Given our first purpose of the paper, to explore how research paradigms shaped our program decisions and research design, it is important to make the paradigm we are working from transparent. We work with, and from, the following definition of narrative inquiry.

Narrative inquiry, the study of experience as story, then, is first and foremost a way of thinking about experience. Narrative inquiry as a methodology entails a view of the phenomenon. To use narrative inquiry methodology is to adopt a particular view of experience as phenomenon under study. (Connelly \& Clandinin, 2006, p. 375) 
Understanding, as Dewey (1938) does, that experiences grow out of past experiences and lead into future experiences, we purposefully returned to earlier experiences that shaped how we imagined implementing a health and wellness program while living alongside urban Aboriginal children and youth in a narrative inquiry. We came to these programs and research decisions with experiences of being passionate about sport, movement, and health in our lives and our work. We had experiences of being alongside youth as teachers, counselors, and youth workers, who worked alongside children and youth in community. We had spent time in relationship and in ceremony with Elders and knowledge keepers that also helped us to think carefully about the details of the proposed study, including the commitment to honour the relationships and to take care of the stories of children and youth in relationally ethical ways (Clandinin \& Connelly, 2000).

As we imagined the narrative inquiry, Lee and Sean were new Assistant Professors at the University of Regina, Saskatchewan. Brian Lewis, a doctoral student, was a physical education consultant in the city. We (Sean and Lee) inquired into our past experiences of beginning narrative inquirers, and understood the importance of working alongside others in a research community. Working alongside others in project communities and response communities (Clandinin, 2013; Lessard, 2014), we knew collaborative work informed how we were imagining the narrative inquiry. We remained open to multiple plotlines, and listened closely to community members, youth, Elders, knowledge keepers, and educators as we searched for a place to situate the program and the research. As we moved to live out both the program purposes and the inquiry purposes, we were awake to the knowledge that we embodied but, given our paradigmatic commitments, like others (Gonzalez, Moll, \& Amanti, 2005) we were also awake to how the communities embodied knowledge; the children, youth, and families would shape both the program and the research.

Given our commitments as academics, we were attentive to the multiple narratives that shaped the funding agency and the public stories that lived around the program purposes of health and wellness for Aboriginal children and youth, in most cases underscored by intervention and prevention. Paying particular attention to our own research paradigms awakened us to the larger social, cultural, and institutional narratives that shaped all of us. Working with a narrative conception of experience, Clandinin and Rosiek (2007) pointed out that

Framed within this view of experience, the focus of narrative inquiry is not only on individuals' experience but also on the social, cultural, and institutional narratives within which individuals' experiences are constituted, shaped, expressed, and enacted. Narrative inquirers study the individual's experience in the world, an experience that is storied both in the living and telling and that can be studied by listening, observing, living alongside one another and writing and interpreting texts. (pp. 42-43)

Attending to the larger social narratives in relation to the children, youth, and their families' experiences in relation to the dominant stories of how to conduct research, both ethically and methodologically, provides a conceptual frame to think about the complexities of creating a research space and wellness program alongside Aboriginal youth in a community. We are compelled to illustrate and share these 
tensions and bumping places as others consider research with Aboriginal youth in Indigenous community contexts.

\section{Shaping a Research Puzzle in the Midst of Creating a Program}

There were multiple social, cultural, and institutional narratives at work as we tried to coordinate program purposes set by the agency from what we saw as research purposes. Given an in-depth literature review, we were aware that the dominant narratives around Aboriginal youth and their families were stories that often called for intervention programs, (Halpern, 2002) for ways to attend to the deficits or deficiencies with which they were viewed (Kremer, Maynard, Polanin, Vaughn, \& Sarteschi, 2015). We were also aware that there were pressures to engage in research, which resulted in measurable outcomes, generalizable indicators that would signify success of the wellness program. We knew these dominant narratives had shaped our personal practical knowledge (Clandinin, 1985) and structured the storied professional knowledge landscapes (Clandinin \& Connelly, 1995) that we most often travelled within. Our research puzzle shifted as we tried to come alongside the youth, and to attend to who they were and were becoming. We began to struggle with how to sustain a wellness program and not slide into dominant constructions of Aboriginal youth. We attempted to hold a firm commitment to co-creating an ethical narrative inquiry space (Ermine, 2007; Clandinin et al., 2015) where Aboriginal children and youth and their community were the primary knowledge holders. By rooting ourselves in experience and taking measures to actively resist the dominant narratives that story Aboriginal children, youth, families, and their communities as "in need," or "in deficit," we co-created a space that opened up new understandings and conceptions of knowledge that would not have been possible otherwise. Quite simply, we learned by moving in a different direction alongside children, youth, and their community.

\section{Methods}

From September 2013 to present date we have been engaged in an afterschool, outside of school, program alongside urban Aboriginal youth. Given our interests in physical education and wellness, we used these content areas to organize structured and purposeful experiences around play and movement. We know from our literature review, and from our experiences, that the phrase "after school programs" brings images of dropping in, hanging out, shooting hoops, playing floor hockey, or throwing dodge balls. Wanting to be clear that this program was different, it was our purpose to ensure that each engagement with the youth had components celebrating the physical, emotional, social, and spiritual wellness of children and youth within their community contexts. Given our backgrounds in physical and health education and experiences working alongside Indigenous communities across Canada, we intended to create meaningful and developmental physical and health education experiences. Framing the program and research around wellness allowed us to move beyond physical experiences to our guiding question and wonder: what does it really mean to live well?

We co-composed a variety of field texts with the youth including conversations, observations, digital stories, and program evaluation surveys. However, this paper is specifically focused on the questions that came about as tensions arose when we attempted to organize both the after-school wellness program 
and research for the after-school wellness program. We came to see these tensions as moments to think deeply about why we felt uneasy about the process. It seems these moments of questioning often moved us beyond the taken-for-granted notions of how things work. Seeing otherwise often times creates moments of tension that can open up opportunities to slow down, to wonder why (Huber, Murphy, \& Clandinin, 2011).

Through narrative inquiry, experience is studied through explorations of the personal/social, temporality, and place. For example, as we experienced these tensions we engaged in research conversations with each other asking questions which explored our (personal) feelings, hopes, and dispositions, the social, that is, what was happening around us, temporality, that is, how our experiences were bound in time, and finally, place(s) "which attends to the specific concrete physical and topological boundaries of inquiry landscapes" (Clandinin \& Connelly, 2000, p. 51).

While there were many bumping places along the way, through our inquiry into these bumping places we identified specific tensions that seemed to weave their way through the project. In what follows we illustrate these tensions as well as in closing possible ways forward in this work.

\section{Storied Landscapes in the Midst of Interventions and Deficit Model Programming}

Statistically, more than half of the Canadian Aboriginal population is under the age of 25. In addition, $3.8 \%$ of Canada's population is of First Nation, Métis, or Inuit ancestry with $54 \%$ of the population residing in urban settings (Canadian Census, 2006, 2011). The self-identified Aboriginal population of Saskatchewan, the Canadian province where this study is situated, is approximately $16 \%$ with $8.3 \%$ of the population residing in Regina, Saskatchewan (Statistics Canada, 2010). Our current study is situated at a time and within a place where the population of Indigenous peoples, particularly Indigenous youth in Canada, is steadily rising in urban settings.

Nationally there are statistical increases in the levels of Aboriginal incarceration rates, unemployment, poverty, and children in care (Findlay \& Weir, 2004).

At-risk youth are commonly defined as having (a) low academic performance; or (b) characteristics typically associated with lower student achievement, including low socioeconomic status (SES), racial, or ethnic minority background, and a single-parent family (Miller, 1993). While purposes for programs for at-risk youth are diverse, they usually include decreasing crime and violence, decreasing substance abuse, social issues, and mental health. In general, we also found that programs also included the importance of increasing academic performance and achievement (Kremer et al., 2015). We also noted that many programs were simply an extension of the school day, an opportunity to do more school (Zief, Lauver, \& Maynard, 2006; Vandell et al., 2005).

From our literature review we got the sense that many of the models being used in after-school programming positioned the youth as at-risk or needing to be skilled up in some form so that they could become better citizens, and achieve higher academic and worldly standards. Program and research implementation, albeit positive in some ways, situated researchers at one end of a knowledge spectrum, 
and children, youth, and families at the other end. That is the researchers and programmers had the knowledge and the children, youth and families did not.

This type of paradigm presumes that the researchers are the sole knowledge holders; they are the experts that have the epistemological understanding needed to in many ways to intervene for the youth and help them get to a better place in their lives in order to accomplish better life outcomes (health, wellness, fitness, academics, opportunity). Further to this, many of the aforementioned paradigms within the literature seek to perceptually or we might suggest politically, sprinkle the modelling with quasi-cultural, effervescent tones of medicine wheels and totem teachings that are at the very least mis-educative (Dewey, 1938), and at the very worst, exemplars of cultural appropriation further enhancing the colonial relationship that at times is reinforced through research. This way of seeing the world makes certain assumptions about knowledge, whose knowledge counts, which knowledge counts, and how certain types of knowledge can be absorbed to fit Western paradigms. Given our ontological commitment to experience and in relation to the Indigenous community, reflectively it becomes easy to see how the cocreated narrative inquiry space that values a storied landscape and children, youth and community experiences bumps hard at times, in many ways violently, with a model that presumes the participant and community as non-knowledge holders.

\section{Relational Ethics in the Midst of Institutional Ethics}

Our past experiences working with narrative inquiry, and in Indigenous and non-Indigenous communities, told us that children, youth, their families, and the communities they lived in carried with them an embodied knowledge (Clandinin \& Connelly, 1995) that would help shape both the wellness program and the research alongside the program. Our program and research also drew on the work of other narrative inquirers (Clandinin, Steeves, \& Caine, 2013; Young, 2005; Lessard, 2013, 2015) who shaped our thinking throughout showing the possibility of learning about the experiences of Aboriginal youth and families through narrative inquiry. From our experiences and from the literature, we understand more fully the relational ethics that are necessary in engaging in narrative inquiry in ways that attend to the lives of both researchers and participants (Clandinin \& Caine 2012; Bergum \& Dossetor, 2005; Menon, Redlich-Amirav, Saleh, \& Kubota, 2015). However, we learned early on that the university ethics board application did not frame experience or ethics in the same way we had come to see it.

We are not the first researchers to see the problematic nature of institutional review boards and their many rules and regulations that don't align with many qualitative research methodologies, in this case narrative inquiry research (Clandinin \& Connelly, 2000; Clandinin, 2013; Josselson, 2007). As spoken about in the research design, we did not want to enter into this particular research space as the experts, or as the sole knowledge holders. The institutional ethics application wanted us to know how many "interviews" we would conduct, how many participants we would "gather data from," and quite problematically, what we would "find" before we even began the research. We should note here that we understand the importance of university ethics boards and support the ways in which they hold researchers to a high standard of ethical care. Yet, as we filled in the small drop-down boxes that 
described our study and the youth we would research alongside, we could not help but begin to feel tension working within these views embedded within the ethical application.

We wondered about the dis/ease we experienced as we filled out the application. The institutional ethics positioned us as experts; as the knowledge holders. While this may be fitting for someone entering with an epistemological framework, model, or intervention, for us, as narrative inquirers, entering with an ontological frame that positions lived experiences as the starting point, this bumped with our philosophical understandings. Beginning with an ontological commitment denotes that we have wonders about experience, about how individuals come to make up their own realities based on their past, present, and imagined experiences. For us to attend to these experiences, we have to be wary that we do not enter with a theoretical frame about how the world works, thus discounting experiential knowledge (Clandinin \& Rosiek, 2007; Clandinin, Schaefer, \& Downey, 2014).

\section{Tentativeness in the Midst of Certainty}

Along with university ethics, based on our granting applications we were expected to meet certain deliverables that were time sensitive. While we fully take responsibility for creating these deliverables, we felt a disconnect in how the funders had envisioned these deliverables being met. We found that many funders still valued positivistic tendencies that position reality outside of experience. It was the quantitative, objective, measures that would be important in showing how effective our program had been. We assume from the funders' perspective that these types of data carry more validity when presented to upper administration. Positioning reality outside of experience, also offers a perceived generalizability that could then be implemented in any context. In this way, it gives data users "definite knowledge" of the program to inform others, or to perhaps implement the program in decontextualized ways.

"In narrative thinking, interpretations of events can always be otherwise. There is a sense of tentativeness, usually expressed as a kind of uncertainty, about an event's meaning" (Clandinin \& Connelly, 2000, p. 31). In the various field texts collected, we felt a great dis/ease in attempting to interpret these data as definite. We now see the disease, the tension, stemmed from trying to reduce this data, to decontextualize it. In decontextualizing it, we lose the embodied knowledge of the community. The sociality, temporality, and place of experience becomes unimportant; they become sanded away (Schaefer \& Clandinin, 2011). We sand away the conversations with Grandma Rose who took us home for tea and told us about what living well meant for her and her grandchildren. The insights gained from community knowledge holders that included the linguistic, historical, cultural, and institutional stories of this community get sanded down to a program that could be implemented in any community. Jade's yellow dress, Colt's puppy, and our numerous conversations with Elders and knowledge keepers about how movement is "good medicine" (Joseph N., personal conversation, May 2015), are seen as additives, as the bow instead of the present. 


\section{Moving Slow in the Midst of Productivity}

Being committed to narrative ways of understanding, and, in turn, to beginning ontologically with experience, as all narrative inquirers begin, takes a great deal of time, patience, and listening. In the context of many Indigenous communities, these commitments draw attention to the many protocols that are contextual to each community, geographical in nature and need to be followed to enter a community in ethically responsive ways. A process that for our research team began with taking tobacco as a form of spiritual offering to an Elder and community knowledge holder to actually find out what the protocols of the community are and how we might form relationships in a good and respectful way alongside Aboriginal children, youth, and their families. In this community, we were physically located in Treaty 4 territory, the ancestral home of the Cree, Saulteaux, and Metis peoples, a geographical place with meaning and relationships that are tied and connected to the histories and the place. These considerations and protocols that we followed were understood through our prior experiences alongside Elders and knowledge keepers in our lives. While designing the program without consultation and relationship with students, community, Elders, and other knowledge holders would have been much more efficient, our ontological commitment to experience cautioned us against hastily setting up a program and research space that did not include these important first steps.

We moved slowly through the process and we paid attention to the details by attending to the silences, the gaps, and the many conversations that helped us understand further how we might co-compose both a program and research space. Collecting data quickly, analyzing it, interpreting it from our own perspectives and writing papers about it would also have been much more efficient and much more productive from a certain stance in research. However, an ontological commitment to experiences requires co-composed relations and processes that include a co-composition of field texts, a co-creation of narrative accounts as we interpret what we have found, and often times a co-writing of final research texts with participants. Thus, moving quickly, moving in ways that dominant stories of research may see as productive, was not an option within the community.

As can be imagined, this process of moving slow created tension. It seemed to be the opposite of what the academic professional knowledge landscape formally and informally prescribed. While we had secured funding for both the program and the research alongside the program, the questions now turned to scaling up, publications, research impact, and other forms of knowledge translation. For early career and experienced researchers, it can be easy to get caught up in the sociality of being an academic. The social aspects that are imbued with publish or perish, personal feelings of guilt, inadequacy, that come from not publishing. Truthfully, it became very difficult at times to not forgo our initial commitment to the children, youth, and community as embodied knowledge holders as we questioned if what we were doing made sense in the realm of academia.

We want to unpack this conceptualization of moving slow alongside children and youth, the community, and each other in an attempt to share these important processes with other researchers as we consider ways to take these experiences back to the community at all times. Paying particular attention to moving slow, in some paradigms, could be considered deficit or lagging behind; less than what others might 
perceive to be as more timely, immediate, valid, or productive research. Here we draw on the introductory narrative to help us illustrate what we mean by moving slow. While moving slow takes more time, moving slow also transcends temporal implications. Converging in a circle at the beginning of each program day, creating a space for the youth to sit and listen alongside one another, responding to others, and sharing a snack, was difficult at first. The youth's stories of the gymnasium space during school hours bumped with sitting, listening, and sharing with others. They had come to know this space differently. Their stories of the gymnasium included chaos, equipment, competing, and what we perceived as a space that was not conducive to conversation and in many ways not conducive to building and acknowledging relationships through movement trying to understand.

The sharing circle that we engaged in each time we met was slow and patient; it took time. In fact, it took almost a year for the circle at the start of each program day to become a routine, to become what was expected within the space. It's just a circle. Simply put. And yet, through this time a space evolved that was attentive to relationships, and attentive to experience that took care of one another's stories, both children's and adults', in a good way. This time and intentional process allowed us to "attend both to personal conditions and, simultaneously, to social conditions" (Clandinin et al., 2013, p. 40) and pay attention to the relational three-dimensional narrative inquiry space (sociality, temporality, place). The students' experiences and knowledge counted during this time. At different times each of our daughters were welcomed to this circle by the youth, as the children and youth from the program metaphorically and physically wrapped their arms around them and included them in the day's activities, welcoming them to their place. Stories of Jade's yellow dress and the small sharing of children and youth stories around the circle each week helped us to better understand how they have come to understand health and wellness, and to notice the importance of moving slow in relationship alongside one another. It is in this way the ideas, philosophy, and the concepts around what it means to live well, to be well as an Aboriginal child, youth, and community member in this particular place and time looked markedly different and sounded different than what we might have initially expected.

\section{Discussion}

We end by returning to the two purposes of this paper: 1) to explore how a particular ontological commitment to experiences shaped both a program and research space focused on wellness. 2) to illustrate the tensions that arose as our commitments to narrative inquiry bumped with the dominant stories of research. Based on our literature review, we are aware that many programs created for Aboriginal youth begin with at-risk frameworks that position the youth as in-deficit, needing to be fixed up. Unfortunately, these frameworks often times discount the lived experiences, the lives of children and youth, and the stories of the community landscapes upon which they live.

We are well aware that not all researchers will be motivated to take up a narrative inquiry, or for that matter use a research methodology that is attentive to beginning with an ontological commitment. However, what we hope became clear in this paper is that no matter what your methodological commitment is, it is very important to attend to its underpinnings throughout the research process. Wonders surrounding how your methodology situates you within the program and research can help to 
make sense of your commitments. In understanding how you are situated within a space, as researcher, as teacher, as programmer, as outsider, as insider, as oppressor, or perhaps in a different way, will also help in understanding how the youth are situated within your methodology and, in turn, your program and your research. In an Indigenous context, some knowledge keepers would say this is how you are locating yourself. Although positioning youth as knowledge holders may seem like a small decision, it is in fact the decision that framed our entire program and research study.

What we also wanted to begin to illustrate in this paper is that when we begin with an ontological commitment to experience, as narrative inquirers do, the research process often starts long before what we see documented, written in papers or books. However, we argue that documenting this is important. This process is a part of the methods. Taking an Elder or knowledge keeper tobacco at the beginning of the study to follow protocol is indeed a part of the ontological commitment to experience, and thus a part of the research. Conversations with youth about the type of program they see as being meaningful to the community is also a part of positioning them as knowledge holders, and is thus a part of the research process. An invitation to families for a celebratory meal, or to simply watch or play with their children in the program attends to the familial stories, positions families as knowers, and is therefore a part of the research process. Documenting, attending to these processes, helps to show the ethical attention and perhaps rigor involved in the research and program process.

In a similar vein, and with regard to the second purpose of this paper, we have also become aware that a strong commitment and understanding of our ontological commitment to experiences helped us to negotiate and make sense of the many bumping places and tensions that became apparent as we attempted to co-compose a research and program space based around wellness alongside Aboriginal children and youth. As we mention, without our commitments to narrative inquiry, it would have been quite easy to enter with an at-risk type intervention that would have positioned us as the knowledge holders within a community, that at the time, we knew very little about. Tensions with productivity will always be alive and well, perhaps a further understanding of the rigour and ethical work that takes place when we see communities, youth, and families as rich with knowledge will shift stories around how we measure productivity. We have seen universities in Canada recently respond in positive ways to the Truth and Reconciliation Commission document (2015) and the calls to action; we wonder about how rigor and research impact might be measured in multiple ways as researchers work with, instead of on, communities. Perhaps illustrating the work that goes into building ethical relationships alongside Indigenous communities provides a better understanding of how important this is as we attempt to better understand what living well looks like from a variety of perspectives.

Lastly, if we are truly interested in better understanding what living well looks like, feels like, for Indigenous children, youth, families, and communities, what we have learned is that entering with a deficit model is extremely problematic. Not entering in this way is risky. In many ways, it opens up the research and program to other ways of knowing, other ways of understanding what living well might mean with all the potential and possibility of that concept. With this we give up certainty, and in many ways control over which direction the research and program take. For us, as we gave up the certainty, what we gained was a much richer, deeper, understanding of the lives of the youth involved in the 
program. Given what we learn from the trends and tendencies in the literature, we see the need to collaborate with Indigenous youth and their families to inquire into their experiences within multiple contexts, but to do so in ways that are not constrained within the institutional narrative of school, a narrative that has too often overwritten the experiences of Indigenous peoples through scripts (Clandinin, Steeves, \& Caine, 2013) and practices that are potentially oppressive and/or harmful in their intentions.

What does your program do? A question that used to cause great dis/ease, is now easily answered with the response, "it helps us to better understand how amazingly resilient the youth are that we get to work with each week, something we would have completely missed if we had tried to fix them up." On second thought, perhaps this is an intervention program. The youth have intervened on our lives and showed us how much there is to be learned from working alongside them.

The bell rings to signal the end of the school day and the beginning of the program. We gather in a circle. Jade, and Tanya, one of the high school youth, pass around some homemade muffins Jade's Grandma made for us. We begin simply with a wonder about what is new...

\section{References}

Bergum, V., \& Dossetor, J. (2005). Relational ethics: The full meaning of respect. Hagerstown, MD: University Publishing Group.

Cajete, G. (1994). Look to the mountains. Colorado: Kivaki Press.

Chung, S. (2016). A Narrative Inquiry into Aboriginal Youth and Families' Experiences of Belonging as Interwoven with Identity Making. (Doctoral Dissertation Retrieved from https://era.library.ualberta.ca/files/ck0698778p/Chung_Simmee_201609_PhD.pdf)

Clandinin, D. J. (1985). Personal practical knowledge: A study of teachers' classroom images. Curriculum Inquiry, 14(4), 361-385.

Clandinin, D. J. (2007). Handbook of narrative inquiry: Mapping a methodology. Thousand Oaks, CA: Sage Publications.

Clandinin D.J., (2013). Engaging in narrative inquiry. Left Coast Press: Walnut Creek

Clandinin, D. J., \& Caine, V. (2012). Narrative inquiry. In A. A. Trainor \& E. Graue (Eds.), Reviewing qualitative research in the social sciences (pp. 166-179). New York: Routledge.

Clandinin, D. J., \& Connelly, F. M. (1995). Teachers' professional knowledge landscapes. New York: Teachers College Press.

Clandinin, D. J., \& Connelly, F. M. (2000). Narrative inquiry. Experience and story in qualitative research. San Francisco: Jossey-Bass. 
Clandinin, D. J., Long, J., Schaefer, L., Downey, C. A., Steeves, P., Pinnegar, E., et al. (2015). Early career teacher attrition: Intentions of teachers beginning. Teaching Education, 26(1), 1-16.

Clandinin, D. J., Schaefer, L., \& Downey, A. (2014). Narrative conceptions of knowledge: Towards understanding teacher attrition. London: Emerald.

Clandinin, D.J., Steeves, P., \& Caine, V. (Eds.). (2013). Composing lives in transition: A narrative inquiry into the experiences of early school leavers. Emerald Group Publishing Limited.

Clandinin, D. J., \& Rosiek, J. (2007). Mapping a landscape of narrative inquiry: borderland spaces and tensions (pp. 35-75) in Clandinin, D. J. (Ed.) Handbook of narrative inquiry: Mapping a methodology. London: Sage.

Connelly, F. M., \& Clandinin, D. J. (1999). Shaping a professional identity: Stories of educational practice. London, ON: Althouse Press.

Connelly, F. M., \& Clandinin, D. J. (2006). Narrative inquiry. In J. Green, G. Camilli, \& P. Elmore (Eds.), Handbook of complementary methods in education research (pp. 375-385). Mahwah, NJ: Lawrence Erlbaum

Dewey, J. (1938). Experience and education. New York: Collier.

Ermine, W. (2007). The ethical space of engagement. Indigenous Law Journal, 6(1), 193-201.

Gonzalex, N., Moll, L, \& Amanti, C. (Eds.). (2005). Funds of knowledge: Theorizing practices in households, communities and classrooms. Mahwah, NJ: Lawrence Erblaum.

Halpern, R. (2002). A different kind of child development institution: The history of after-school programs for low-income children. Teachers College Record, 104(2), 178-211.

Huber, J., Murphy, M., \& Clandinin, D. (2011). Places of curriculum making: Narrative inquiries into children's lives in motion. Bingley: Emerald.

Josselson, R. (2007). The ethical attitude in narrative research. In Jean Clandinin (Ed.), Handbook of narrative inquiry: Mapping a methodology (pp. 537-566). Thousand Oaks, CA: Sage.

Kremer, K. P., Maynard, B. R., Polanin, J. R., Vaughn, M. G., \& Sarteschi, C. M. (2015). Effects of afterschool programs with at-risk youth on attendance and externalizing behaviors: A systematic review and meta-analysis. Journal of Youth and Adolescence, 44(3), 616-636.

Lessard, S. (2013). A narrative account of Skye. In D.J. Clandinin, P. Steeves, \& V. Caine (Eds.). Composing lives in transition: A narrative inquiry into the experiences of early school leavers. London: Emerald.

Lessard, S. (2014). Red Worn Runners: A narrative inquiry into the stories of Aboriginal youth and families in urban settings. Unpublished doctoral dissertation, University of Alberta, Edmonton, Canada.

Lessard, S. (2015). Worlds of curriculum making: Familial curriculum-making worlds and school curriculum-making worlds. Journal of Family Diversity in Education, 1(3), 1-16.

Lincoln, Y. S., Lynham, S. A., \& Guba, E. G. (2011). Paradigmatic controversies, contradictions, and emerging confluences, revisited. In N. K. Denzin \& Y. S. Lincoln (Eds.), The Sage handbook of qualitative research (Vol. 4, pp. 97-128). Thousand Oaks, CA: Sage. 
Menon, J., Redlich-Amirav, D., Saleh, M., \& Kubota, H. (2015). Embracing lived multiplicities as beginning narrative inquirers. Creative Approaches to Research, 8(3), 80-101.

Miller, B. M. (1993). The literature project: Using literature to improve the self-concept of at-risk adolescent females. Journal of Reading, 36(6), 442-448.

Statistics Canada. (2006). 2006 Census of population (Catalogue Number 97-560-XCB2006028). Retrieved from http://www12.statcan.gc.ca/census-recensement/2006/index-eng.cfm

Statistics Canada. (2010). Projections of the Diversity of the Canadian Population, 2006-2031, Statistics Canada Catalogue no. 91-551.

Statistics Canada. (2011). 2011 National Household Survey (Catalogue no. 99-012-X2011044). Retrieved from http://www12.statcan.gc.ca/nhs-enm/index-eng.cfmhttp://www12.statcan.gc.ca/nhsenm/index-eng.cfm

Truth and Reconciliation Commission of Canada. (2015). Truth and Reconciliation Commission of Canada calls to action. Winnipeg, MB: author.

Vandell, D. L., Shernoff, D. J., Pierce, K. M., Bolt, D. M., Dadisman, K., \& Brown, B. B. (2005). Activities, engagement, and emotion in after-school programs (and elsewhere). New Directions for Youth Development, (105), 121-129.

Young, M. (2005) Pimatisiwin, walking in a good way: A narrative inquiry into language as identity. Winnipeg, MB: Pemmican Publication.

Zief, S.G., Lauver, S., \& Maynard, R.A. (2006). Impacts of after-school programs on student outcomes. Campbell Systematic Reviews. 


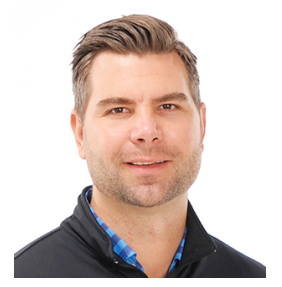

Lee Schaefer, PhD, is an Assistant Professor at McGill University in the Department of Kinesiology and Physical Education. He is also the Chair of the Physical and Health Education Canada Research Council. His research is focused on teacher education, specifically, physical education teacher education, youth development through wellness and physical activity, the impact of the outdoors on youth physical activity levels and narrative inquiry. He has been recognized on a national and international level for both his research and his writing and has been invited to speak at local, national, and international conferences. His passion for physical education, and providing youth purposeful, developmental, movement opportunities, continues to drive his research, teaching, and service commitments.

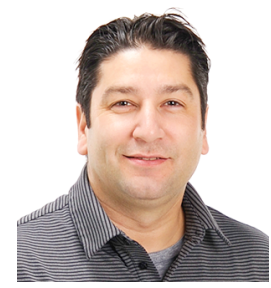

Sean Lessard, PhD, is from Montreal Lake Cree Nation Treaty 6 territory. He is an Associate Professor of Indigenous Education \& Teacher Education at the University of Alberta and co-founder of Growing Young Movers Youth Development. He is an award-winning speaker, writer, and researcher working closely with communities on a national level. Sean's areas of interest include youth mentorship, leadership, high school completion, and transition to postsecondary/workforce strategies. He is the Pat Clifford Award Winner for Emerging Educational research as well as the 2015 Myer Horowitz Outstanding Dissertation Award Winner.

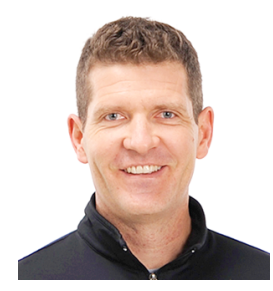

Brian Lewis is a doctoral candidate at the University of Regina and co-founder Growing Young Movers Youth Development. He is the Program Director with G.Y.M., consultant, workshop facilitator, and resource developer in the area of physical education and physical literacy. Currently, Brian sits on the board of directors for Physical and Health Education (PHE) Canada. His interests revolve around the connections between the holistic well-being of youth and its impact on their physical literacy journey. Brian's doctoral research is a narrative inquiry into the experiences of urban Aboriginal youth within an after-school wellness program. 